\title{
Preoperative computed tomography angiography (CTA) of the body in vascular patients: prevalence and significance of unsuspected extravascular findings
}

\author{
Präoperative computertomografische Angiografie (CTA) des \\ Rumpfes von Patienten der Gefäßchirurgie: Prävalenz und \\ Signifikanz unerwarteter extravaskulärer Befunde
}

Authors

Larissa Sarah Turowski ${ }^{1}$, Marco Dollinger ${ }^{1}$, Walter A. Wohlgemuth ${ }^{2}$, Moritz Wildgruber ${ }^{3}$, Lukas Philipp Beyer ${ }^{1}$, Karin Pfister ${ }^{4}$, Christian Stroszczynski ${ }^{1}$, René Müller-Wille ${ }^{5}$

Affiliations

1 Radiology, University Medical Center Regensburg, Regensburg, Germany

2 Radiology, University-Medical-Center Halle, Halle (Saale), Germany

3 Department of Clinical Radiology, University-MedicalCenter Münster, Münster, Germany

4 Department of Vascular and Endovascular Surgery, University-Medical-Center Regensburg, Regensburg, Germany

5 Department of Radiology, University Medical Center Göttingen, Göttingen, Germany

Key words

CT-angiography, neoplasms, aorta

received 17.06.2018

accepted 24.10.2018

Bibliography

DOI https://doi.org/10.1055/a-0775-2544

Published online: 31.1.2019

Fortschr Röntgenstr 2019; 191: 716-724

(c) Georg Thieme Verlag KG, Stuttgart · New York ISSN 1438-9029

Correspondence

Larissa Sarah Turowski

Radiology, University-Medical-Center Regensburg, Franz-Josef-Strauss-Allee 11, 93053 Regensburg,

Germany

Tel.: ++ 49/1525/3479039

larissa.turowski@gmx.de

\section{ZUSAMMENFASSUNG}

Ziel Evaluation der Prävalenz und Signifikanz von unerwarteten extravaskulären Befunden in Ganzkörper-computertomografischen Angiografie-Scans (CTA) vor endovaskulärer oder chirurgischer Behandlung von Gefäßpatienten.

Material und Methoden Diese Studie wurde von der örtlichen Ethikkommission genehmigt. Es wurden radiologische Befunde von Patienten, die eine Ganzkörper-CTA im Zeitraum zwischen Januar 2004 und Dezember 2014 vor endovaskulärer oder chirurgischer Therapie von Erkrankungen der Gefäße erhielten, retrospektiv aufgearbeitet. Alle unerwarteten extravaskulären Befunde wurden als klinisch nicht relevant (Verlaufskontrollen nicht indiziert) oder klinisch relevant (Verlaufskontrollen/sofortige Behandlung indiziert) klassifiziert. Der weitere Verlsauf von Patienten mit klinisch relevanten extravaskulären Befunden wurde retrospektiv evaluiert.

Ergebnisse Es wurden 806 Patienten in diese Studie eingeschlossen (592 Männer; Durchschnittsalter 67 Jahre). Bei 778 (96,5\%) von 806 Patienten wurden insgesamt 3293 extravaskuläre Zufallsbefunde festgestellt. Darunter befanden sich 259 suspekte Befunde bei 205 Patienten (25,4\%), die Verlaufskontrollen oder eine sofortige Behandlung erforderten. Ein bis dahin unbekanntes Malignom wurde bei 23 Patienten (2,9\%) diagnostiziert, darunter waren 10 Patienten (1,2\%) mit einem Lungenkarzinom. Bei Männern wurden mehr maligne Tumoren nachgewiesen als bei Frauen (3,5\% versus $0,9 \% ; p=0,055$; Fisher-Test). Patienten mit einem zufällig entdeckten malignen Tumor waren signifikant älter als Patienten ohne Tumorbefund (Durchschnittsalter 72,3 vs. 67,5 Jahre; $p=0,0432$; t-test).

Fazit Klinisch relevante extravaskuläre Zufallsbefunde treten häufig auf bei Gefäßpatienten. Besonders beachtenswert sind maligne Tumoren der Lunge. 


\section{Kernaussagen}

- Bei $25,4 \%$ der Patienten wurden klinisch relevante extravaskuläre Zufallsbefunde diagnostiziert.

- Die Inzidenz maligner Tumoren lag bei 2,9\%

- Das Bronchialkarzinom hat unter den Malignomen die höchste Inzidenz (1,2\%).

\section{ABSTRACT}

Purpose Evaluation of the prevalence and significance of unsuspected extravascular findings on computed tomography angiography (CTA) of the body before endovascular or surgical treatment in vascular patients.

Materials and Methods This study was approved by the local institutional review board. Radiology reports of 806 patients who underwent CTA of the body during January 2004 until December 2014 before endovascular or surgical treatment of vascular diseases were retrospectively reviewed. All unexpected extravascular abnormalities were classified as clinically non-significant (requiring no follow-up) or clinically significant (requiring further follow-up/immediate treatment). The course of patients with significant extravascular findings was retrospectively evaluated.

Results Overall 806 patients were included in this study (592 men; mean age: 67 years). In 778 (96.5\%) of 806 patients
3293 incidental extravascular findings were diagnosed. There were 259 suspicious findings in 205 patients (25.4\%) that required further follow-up or immediate treatment. A previously unknown malignant tumor was diagnosed in 23 (2.9\%) patients. 10 patients $(1.2 \%)$ were diagnosed with lung cancer. Malignant tumors were detected more often in men than in women (3.5\% versus $0.9 \%$ ). Patients with an incidental tumor were significantly older than patients without a tumor (mean age: 72.3 vs. 67.5 years).

Conclusion Clinically significant unexpected extravascular findings are common in vascular patients. Especially noteworthy are malignant tumors of the lung.

\section{Key points}

- Clinically relevant extravascular findings were detected in $25.4 \%$ of the patients.

- The incidence of malignant tumors was $2.9 \%$.

- Lung cancer had the highest incidence among all malignancies (1.2\%).

\section{Citation Format}

- Turowski LS, Dollinger M, Wohlgemuth WA et al. Preoperative computed tomography angiography (CTA) of the body in vascular patients: prevalence and significance of unsuspected extravascular findings. Fortschr Röntgenstr 2019; 191: 716724

\section{Introduction}

Multislice spiral computed tomography angiography (CTA) of the body is a widely used and recommended imaging modality before endovascular and surgical treatment of aortic aneurysms and occlusive disease of the great arteries. For the planning of both endovascular and surgical treatment, the scan includes the body of the patient from neck to groin as a standard feature. As a result, the entire arterial system within this area gets depicted. This approach is required to plan the intervention of the current vascular disease [1, 2]. However, besides vascular structures, all of the surrounding organs of the thorax, abdomen and pelvis are completely depicted by CTA without an additional dose and this data has to be carefully evaluated. The objective of this study was to evaluate the incidence and clinical significance of unexpected extravascular findings in patients undergoing whole-body CTA before endovascular or surgical treatment in a large patient population.

\section{Materials and methods}

\section{Patients}

This retrospective single-center study was approved by the local institutional review board. We reviewed all vascular patients who underwent CTA at our university hospital between January 2004 and December 2014, whose CT scans fulfilled the following criteria:

1. Only the first available preoperative CTA was included.

2. Externally performed CT scans were not considered.

3. The CTA dataset included the entire thorax, abdomen, and pelvis.

The indications for CTA are specified in $>$ Table 1.

\section{Image acquisition}

During the study period two different multiple detector computed tomography (MDCT) scanners were used at our university hospital (Somatom Sensation 16 and Somatom Flash Dual Source; Siemens, Erlangen, Germany). Scans were usually performed after power injection of $90-160 \mathrm{ml}$ of non-ionic contrast agent (e. g. Ultravist 370, Bayer-Schering AG, Berlin, Germany) at a rate of $3-4 \mathrm{~mL} / \mathrm{s}$. For image analysis transverse and coronal planes with a slice thickness of $3.0 \mathrm{~mm}$ were reconstructed (kernel: B26f), supplemented with parasagittal planes to detect pathologies of the aortic arch. A lung window with a slice thickness of $5.0 \mathrm{~mm}$ (kernel: B60f) in transverse and coronal planes was calculated for all patients. All CTA datasets were stored digitally in our Picture Archiving and Communication System (PACS).

\section{Image analysis}

A retrospective analysis of the digitally stored final radiology reports was done by the study coordinators (author \#1 and author \#8) in consensus. All images were originally evaluated by both a resident and a senior radiologist. Any documented unexpected extravascular abnormality was classified into one of two groups by the study coordinators based on their expected clinical relevance. The first group comprised patients with clinically non-significant extravascular findings, who did not require additional follow-up or treatment. The second group encompassed patients with unsuspected clinically significant extravascular findings requiring further examination or immediate treatment. 
- Table 1 Main indication for CTA in 806 vascular patients.

- Tab. 1 Indikation für eine CTA bei 806 Patienten der Gefäßchirurgie.

\begin{tabular}{|l|r|r|r|r|}
\hline main indication for preoperative CTA & $\mathbf{n}$ & $\mathbf{( \% )}$ & mean age (range) & gender male \\
\hline aortic aneurysm & 474 & $(58.8)$ & $71(36-91)$ & $375(79.1 \%)$ \\
\hline aortic dissection & 97 & $(12.0)$ & $57(20-84)$ & $61(62.9 \%)$ \\
\hline penetrating atherosclerotic ulcers & 15 & $(1.9)$ & $72(56-82)$ & $12(80.0 \%)$ \\
\hline arterial stenosis & 141 & $(17.5)$ & $68(21-91)$ & $100(70.9 \%)$ \\
\hline - aorta & 18 & $(2.2)$ & & \\
\hline - supraaortic arteries & 42 & $(5.2)$ & & \\
\hline - visceral arteries & 13 & $(1.6)$ & & \\
\hline - Iliac arteries & 68 & $(8.4)$ & & $26(52.0 \%)$ \\
\hline detection of embolic sources & 50 & $(6.2)$ & $69(38-90)$ \\
\hline miscellaneous & 29 & $(3.6)$ & $70(46-91)$ \\
\hline
\end{tabular}

\section{Clinical outcomes}

The course of the patients in the second group was retrospectively evaluated by using our medical database and by analyzing all available follow-up images. Non-calcified solid pulmonary nodules were retrospectively processed according to the guidelines from the Fleischner Society [3]. Lymph nodes $>10 \mathrm{~mm}$ (short axis) were considered to be a significant finding. Cystic formations of the kidneys were categorized according to the Bosniak classification system [4]. Significant extravascular findings that were already documented in the patient's medical history were not taken into account.

\section{Statistical analysis}

Fisher's exact test and t-test were used. A p-value (two-sided) of 0.05 is considered statistically significant. Data entry and calculations were made with the software package SPSS (Chicago, EUA).

\section{Results}

Between January 2004 and December 2014, 806 patients (mean age: 67 years; range: 20 - 91 years) fulfilled the inclusion criteria. 592 (73.4\%) of those were male (mean age: 67 years; range: 20 91 years), and 214 (26.6\%) were female (mean age: 70 years; range: 25 - 91 years). A total of 3293 incidental extravascular findings were diagnosed in 778 patients (778/806; 96.5\%). The results of clinically non-significant and significant findings are summarized in Tables 2 and 3.

\section{Non-significant findings}

Most unsuspected extravascular findings had no further consequences for the patients (3034/3293; 92.1\%). Overall, non-significant extravascular findings were diagnosed in 768 patients (768/806; $95.3 \%$ ). Degenerative spine disease/arthrosis (433/806; $53.7 \%$ ), benign simple renal cysts (270/806; $33.5 \%$ ), goiter (227/806; $28.2 \%$ ) and asymptomatic colonic diverticula (202/806; $25.1 \%$ ) were the most frequent non-significant findings ( $\bullet$ Table 2 ).

\section{Significant findings}

259 of 3293 findings (7.8\%) in 205 patients (205/806; 25.4\%) required further clinical follow-up, imaging or immediate treatment ( $\triangleright$ Table 3$)$. In $60.5 \%$ of the patients (124/205), the significant finding was located in the thorax. Most clinically significant extravascular findings were lesions or signs potentially suspicious of malignancy (196/259; 75.7\%). Those were found in 164 patients (164/806; 20.3\%).

\section{Non-malignant findings}

The incidences of significant non-malignant findings are summarized in $>$ Table 3 . The most frequently detected, clinically relevant non-malignant findings were abnormalities suspicious of pulmonary infection (29/806; 3.6\%). After additional workup, systemic antibiotic therapy was started in $11(11 / 29 ; 37.9 \%)$ of these patients. Interlobular septal thickening due to interstitial pulmonary edema was noted in 11 patients $(11 / 806 ; 1.4 \%)$ and diuretic therapy was started in all of those cases. A chest drainage tube was placed after CTA in 6 patients with extensive pleural effusion (6/806; $0.7 \%)$ and in 1 patient with coincidentally detected pneumothorax (1/806; $0.1 \%)$. In 5 patients (5/806; $0.6 \%$ ) pulmonary embolism was diagnosed and anticoagulation therapy was initiated in all of them. Reticular opacities suspicious of pulmonary fibrosis were detected in 4 patients (4/806; $0.5 \%$ ) and further examination was recommended. Relevant non-malignant abdominal findings were hydronephrosis grade 2 or higher in 4 patients (4/806; $0.5 \%) .2$ patients (2/806; $0.2 \%$ ) had an acute rib fracture. In 1 patient $(1 / 806 ; 0.1 \%)$ acute spondylodiscitis was diagnosed and subsequently treated with systemic antibiotics.

\section{Malignant findings}

The most frequent potentially malignant findings were non-calcified solid pulmonary nodules (59/806; $7.3 \%$ ). High-risk patients with nodules of $\leq 6 \mathrm{~mm},>6-8 \mathrm{~mm}$ and $>8 \mathrm{~mm}$ had follow-up data available in $40.0 \%(2 / 5), 58.1 \%(18 / 31)$ and $73.9 \%(17 / 23)$ 
- Table 2 Non-significant extravascular findings.

- Tab. 2 Klinisch nicht relevante extravaskuläre Zufallsbefunde.

\begin{tabular}{|c|c|c|c|}
\hline region & findings & $\mathbf{n}$ & $\%$ \\
\hline thyroid gland & goiter & 227 & 28.2 \\
\hline chest wall & lipoma/atheroma/scars & 10 & 1.2 \\
\hline \multirow[t]{2}{*}{ breast } & gynecomastia & 24 & 3.0 \\
\hline & calcifications, fibroadenoma, dense tissue & 8 & 1.0 \\
\hline \multirow[t]{5}{*}{ mediastinum/hilum } & hiatal hernia & 36 & 4.5 \\
\hline & esophageal diverticulum & 1 & 0.1 \\
\hline & tracheal diverticulum & 1 & 0.1 \\
\hline & lymphocele & 1 & 0.1 \\
\hline & lymph node calcification/fatty degeneration & 23 & 2.9 \\
\hline \multirow[t]{2}{*}{ pleura } & pleural effusion (small, no treatment) & 70 & 8.7 \\
\hline & pleural fibrosis and calcification & 17 & 2.1 \\
\hline \multirow[t]{9}{*}{ lung } & pulmonary emphysema & 182 & 22.6 \\
\hline & subsegmental atelectasis & 167 & 20.7 \\
\hline & parenchymal scars & 167 & 20.7 \\
\hline & bronchiectasis & 9 & 1.1 \\
\hline & bronchial wall thickening (chronic bronchitis) & 3 & 0.4 \\
\hline & pulmonary cavitation & 1 & 0.1 \\
\hline & pneumatocele & 3 & 0.4 \\
\hline & non-calcified solid nodule $\leq 4 \mathrm{~mm}$ (low-risk patient) & 26 & 3.2 \\
\hline & calcified granuloma & 52 & 6.5 \\
\hline \multirow[t]{5}{*}{ liver } & fatty liver & 44 & 5.5 \\
\hline & calcification & 12 & 1.5 \\
\hline & hepatomegaly & 3 & 0.4 \\
\hline & hepatic cysts & 103 & 12.8 \\
\hline & hepatic hemangioma & 59 & 7.3 \\
\hline \multirow[t]{3}{*}{ biliary tract } & cholelithiasis & 76 & 9.4 \\
\hline & porcelain gallbladder & 3 & 0.4 \\
\hline & aerobilia & 2 & 0.2 \\
\hline \multirow[t]{4}{*}{ pancreas } & pancreatic duct calcifications & 7 & 0.9 \\
\hline & pancreatic duct dilatation & 19 & 2.4 \\
\hline & pancreatic pseudocyst & 14 & 1.7 \\
\hline & pancreatic lipomatosis & 51 & 6.3 \\
\hline \multirow[t]{5}{*}{ spleen } & accessory spleen & 54 & 6.7 \\
\hline & calcification & 7 & 0.9 \\
\hline & cyst & 18 & 2.2 \\
\hline & splenosis & 1 & 0.1 \\
\hline & infarction & 4 & 0.5 \\
\hline \multirow[t]{2}{*}{ gastrointestinal tract } & duodenal/jejunal diverticula & 6 & 0.7 \\
\hline & colonic diverticulosis & 202 & 25.1 \\
\hline peritoneal cavity & ascites & 10 & 1.2 \\
\hline mesentery & mesenteric panniculitis & 6 & 0.7 \\
\hline retroperitoneal space & lipoma & 1 & 0.1 \\
\hline
\end{tabular}


- Table 2 (Continuation)

\begin{tabular}{|c|c|c|c|}
\hline region & findings & $\mathbf{n}$ & $\%$ \\
\hline \multirow[t]{3}{*}{ adrenal gland } & adrenal hyperplasia & 74 & 9.2 \\
\hline & adenoma & 44 & 5.5 \\
\hline & calcification & 5 & 0.6 \\
\hline \multirow[t]{4}{*}{ kidney } & renal cysts & 270 & 33.5 \\
\hline & renal parenchymal thinning & 57 & 7.1 \\
\hline & renal infarction & 35 & 4.3 \\
\hline & horseshoe kidney & 1 & 0.1 \\
\hline \multirow[t]{2}{*}{ urinary tract } & urinary calculi (without obstruction) & 19 & 2.4 \\
\hline & bladder diverticulum & 4 & 0.5 \\
\hline abdominal wall & abdominal wall hernia & 36 & 4.5 \\
\hline \multirow[t]{5}{*}{ male reproductive system } & prostatic hyperplasia & 87 & 10.8 \\
\hline & prostatic calcification & 57 & 7.1 \\
\hline & hydrocele & 4 & 0.5 \\
\hline & varicocele & 1 & 0.1 \\
\hline & inguinal hernia & 3 & 0.4 \\
\hline \multirow[t]{2}{*}{ female reproductive system } & uterine fibroid & 20 & 2.5 \\
\hline & ovarian cyst & 10 & 1.2 \\
\hline groin & seroma & 2 & 0.2 \\
\hline \multirow[t]{4}{*}{ musculoskeletal } & degenerative spine disease/arthrosis & 433 & 53.7 \\
\hline & healed fracture & 79 & 9.8 \\
\hline & benign skeletal lesions (cyst/osteoma) & 59 & 7.3 \\
\hline & intramuscular lipoma & 4 & 0.5 \\
\hline
\end{tabular}

of cases, respectively ( $\downarrow$ Table 3 ). Lung cancer was diagnosed in 10 patients (10/806; $1.2 \%$ ) ( Fig. 1 ).

Overall, a previously unknown malignant tumor was diagnosed in $23(2.9 \%)$ patients. The incidence of lung cancer was followed in descending order by colorectal cancer (3/806; $0.4 \%)$, lymphoma/leukemia (2/806; $0.2 \%)$, prostate cancer (2/806; $0.2 \%)$ and other malignancies shown in $>$ Table 3 . In 9 patients (9/806; $1.1 \%)$ metastases were found simultaneously. Malignant tumors were detected slightly more often in men than in women $(3.5 \%$ versus $0.9 \% ; p=.055$ ), but the association was not significant. Patients with a newly diagnosed malignant tumor were significantly older than patients without a malignant tumor $(72.3 \pm 8.2$ years vs. $67.5 \pm 11.3$ years; $p=.0432$ ) ( $\triangleright$ Fig. 2 ).

\section{Discussion}

Computed tomography angiography is a primary imaging modality for planning endovascular and surgical procedures in patients with vascular diseases [1, 2]. Especially for the planning of aortic stent grafts, a preoperative CTA scan is mandatory. However, scans of the entire aorta and the great arteries arising from the aorta include almost the whole chest, abdomen, and pelvis. Therefore, radiologists have to be aware of unexpected clinically relevant extravascular abnormalities. This information is available without an additional X-ray dose. Detection of relevant pathologies may lead to further diagnostics and treatment in succession.

Nearly all patients showed one or more unsuspected extravascular finding on preoperatively performed whole-body CTA. A significant finding was detected in one in four patients. Most significant extravascular findings were located in the thorax (60.5\%). Those were pulmonary infection, interstitial pulmonary edema, extensive pleural effusion and pulmonary embolism. Lung cancer was first diagnosed in $1.2 \%$ of the patients.

Our results are in concordance to the results published by Indes and colleagues, who reviewed the course of 82 vascular patients undergoing whole-body CTA before and after endovascular aneurysm repair (EVAR) [5]. At least one incidental finding was detected in $89 \%$ of their patients, and $19 \%$ were clinically significant. The most common clinically significant incidental finding was the presence of a lung mass in $4.8 \%$ of the patients. In contrast to our results, they detected a slightly higher chance of finding a clinically significant result in women. Furthermore, there was no significant difference between the two groups with respect to patient age (76. 1 vs. 75.5 years). However, their patient population was tenfold smaller than in our study. Our results are not comparable to those studies with vascular patients that analyze CT scans of the abdominal aorta and lower extremities only [6-9]. 
- Table 3 Clinically significant extravascular findings.

- Tab.3 Klinisch relevante extravaskuläre Zufallsbefunde.

\begin{tabular}{|c|c|c|c|c|c|c|c|c|}
\hline \multirow[t]{2}{*}{ region } & \multirow[t]{2}{*}{$\begin{array}{l}\text { clinically significant extravascular } \\
\text { finding }\end{array}$} & \multicolumn{2}{|c|}{ no. of patients } & \multicolumn{2}{|c|}{$\begin{array}{l}\text { follow-up studies } \\
\text { performed }\end{array}$} & \multicolumn{3}{|c|}{ relevant diagnosis/therapeutic consequences } \\
\hline & & $\mathbf{n}$ & (\%) & $\mathbf{n}$ & (\%) & $\mathbf{n}$ & (\%) & \\
\hline chest wall & lesion suspected of malignancy & 1 & $(0.1)$ & 1 & $(0.1)$ & 0 & - & - \\
\hline breast & lesion suspected of malignancy & 2 & $(0.2)$ & 1 & $(0.1)$ & 0 & - & - \\
\hline \multirow[t]{5}{*}{$\begin{array}{l}\text { mediastinum } \\
\text { \& hilum }\end{array}$} & $\begin{array}{l}\text { mass/lymph node enlargement } \\
(>1 \mathrm{~cm})\end{array}$ & 17 & $(2.1)$ & 11 & $(1.4)$ & 1 & $(0.1)$ & leukemia \\
\hline & & & & & & 1 & $(0.1)$ & lymphoma \\
\hline & & & & & & 1 & $(0.1)$ & thymus cancer \\
\hline & & & & & & 3 & $(0.4)$ & metastasis \\
\hline & thickening of the esophagus wall & 7 & $(0.9)$ & 4 & $(0.5)$ & 4 & $(0.5)$ & $\begin{array}{l}\text { esophagitis } \\
\text { (proton-pump inhibitors) }\end{array}$ \\
\hline \multirow[t]{2}{*}{ pleura } & extensive pleural effusion & 6 & $(0.7)$ & 6 & $(0.7)$ & 6 & $(0.7)$ & pleural drainage \\
\hline & pneumothorax & 1 & $(0.1)$ & 1 & $(0.1)$ & 1 & $(0.1)$ & pleural drainage \\
\hline \multirow[t]{11}{*}{ lung } & interlobular septal thickening & 11 & (1.4) & 11 & (1.4) & 6 & $(0.7)$ & lung edema (diuretic) \\
\hline & filling defects in pulmonary artery & 5 & $(0.6)$ & 5 & $(0.6)$ & 5 & $(0.6)$ & $\begin{array}{l}\text { pulmonary embolism } \\
\text { (anticoagulants) }\end{array}$ \\
\hline & reticular opacities (fibrosis) & 4 & $(0.5)$ & 1 & $(0.1)$ & 0 & - & - \\
\hline & tree in bud & 4 & $(0.5)$ & 4 & $(0.5)$ & 2 & $(0.2)$ & $\begin{array}{l}\text { infective bronchiolitis } \\
\text { (antibiotics) }\end{array}$ \\
\hline & ground glass opacity & 3 & $(0.4)$ & 3 & $(0.4)$ & 1 & $(0.1)$ & $\begin{array}{l}\text { infective pneumonia } \\
\text { (antibiotics) }\end{array}$ \\
\hline & consolidation & 22 & $(2.7)$ & 22 & $(2.7)$ & 8 & $(1.0)$ & $\begin{array}{l}\text { infective pneumonia } \\
\text { (antibiotics) }\end{array}$ \\
\hline & non-calcified solid nodule/mass & & & & & & & \\
\hline & - $\leq 6$ mm (high-risk patients) & 5 & $(0.6)$ & 2 & $(0.2)$ & 0 & - & - \\
\hline & . $6-8 \mathrm{~mm}$ & 31 & $(3.8)$ & 18 & $(2.2)$ & 1 & $(0.1)$ & metastasis \\
\hline & - $8 \mathrm{~mm}$ & 23 & (2.9) & 17 & (2.1) & 2 & $(0.2)$ & metastasis \\
\hline & & & & & & 10 & $(1.2)$ & lung cancer \\
\hline liver & lesion suspected of malignancy & 8 & $(1.0)$ & 6 & $(0.7)$ & 3 & $(0.4)$ & metastasis \\
\hline \multirow[t]{2}{*}{ biliary tract } & bile duct dilatation & 3 & $(0.4)$ & 3 & $(0.4)$ & 1 & $(0.1)$ & papillary stenosis (papillotomy) \\
\hline & thickening of the gallbladder wall & 3 & $(0.4)$ & 3 & $(0.4)$ & 1 & $(0.1)$ & cholecystitis (cholecystectomy) \\
\hline pancreas & lesion suspected of malignancy & 6 & $(0.7)$ & 3 & $(0.4)$ & 0 & - & - \\
\hline \multirow[t]{2}{*}{ spleen } & splenomegaly & 8 & $(1.0)$ & 5 & $(0.6)$ & 0 & - & - \\
\hline & lesion suspected of malignancy & 2 & $(0.2)$ & 1 & $(0.1)$ & 0 & - & - \\
\hline \multirow{5}{*}{$\begin{array}{l}\text { gastro-intestinal } \\
\text { tract }\end{array}$} & thickening of the stomach wall & 2 & $(0.2)$ & 2 & $(0.2)$ & 1 & $(0.1)$ & neuroendocrine cancer \\
\hline & thickening of the small bowel wall & 2 & $(0.2)$ & 1 & $(0.1)$ & 0 & - & - \\
\hline & thickening of the large bowel wall & 13 & $(1.6)$ & 12 & (1.5) & 1 & $(0.1)$ & intestinal wall necrosis \\
\hline & & & & & & 2 & $(0.1)$ & $\begin{array}{l}\text { colorectal cancer/high-grade } \\
\text { dysplasia }\end{array}$ \\
\hline & & & & & & 2 & $(0.2)$ & colitis \\
\hline mesentery & lymph node enlargement & 5 & $(0.6)$ & 3 & $(0.4)$ & 1 & $(0.1)$ & metastasis \\
\hline
\end{tabular}


- Table 3 (Continuation)

\begin{tabular}{|c|c|c|c|c|c|c|c|c|}
\hline \multirow[t]{2}{*}{ region } & \multirow[t]{2}{*}{$\begin{array}{l}\text { clinically significant extravascular } \\
\text { finding }\end{array}$} & \multicolumn{2}{|c|}{ no. of patients } & \multicolumn{2}{|c|}{$\begin{array}{l}\text { follow-up studies } \\
\text { performed }\end{array}$} & \multicolumn{3}{|c|}{ relevant diagnosis/therapeutic consequences } \\
\hline & & $\mathbf{n}$ & (\%) & $\mathbf{n}$ & (\%) & $\mathbf{n}$ & (\%) & \\
\hline $\begin{array}{l}\text { retroperitoneal } \\
\text { space }\end{array}$ & lymph node enlargement & 4 & $(0.5)$ & 4 & $(0.5)$ & 0 & - & - \\
\hline adrenal gland & lesion suspected of malignancy & 9 & (1.1) & 7 & $(0.9)$ & 1 & $(0.1)$ & metastasis \\
\hline \multirow[t]{2}{*}{ kidney } & cystic lesions ( $\geq$ Bosniak IIF) & 13 & $(1.6)$ & 5 & $(0.6)$ & 0 & - & - \\
\hline & solid lesions suspected of malignancy & 18 & $(2.2)$ & 9 & (1.1) & 1 & $(0.1)$ & kidney cancer \\
\hline \multirow[t]{3}{*}{ urinary tract } & hydronephrosis ( $\geq$ grade II) & 4 & $(0.6)$ & 3 & $(0.5)$ & 0 & & \\
\hline & lesion suspected of malignancy & 1 & $(0.1)$ & 1 & $(0.1)$ & 1 & $(0.1)$ & urethral cancer \\
\hline & thickening of the bladder wall & 10 & $(1.2)$ & 2 & $(0.2)$ & 1 & $(0.1)$ & bladder cancer \\
\hline \multirow[t]{3}{*}{ musculo-skeletal } & acute fracture (rib) & 2 & $(0.2)$ & 2 & $(0.2)$ & 0 & - & $\begin{array}{l}\text { medical treatment (painkiller/ } \\
\text { pain management) }\end{array}$ \\
\hline & spondylodiscitis & 1 & $(0.1)$ & 1 & $(0.1)$ & 1 & $(0.1)$ & medical treatment (antibiotics) \\
\hline & $\begin{array}{l}\text { lesion suspected of malignancy } \\
\text { (osteolytic/osteoblastic) }\end{array}$ & 3 & $(0.4)$ & 3 & $(0.4)$ & 3 & $(0.4)$ & metastasis \\
\hline
\end{tabular}

In large studies, evaluating coronary artery abnormalities using electro-beam CT (EBCT) or multidetector CT (MDCT), the incidence of lung cancer was about $0.01 \%$ to $0.4 \%$ [10-14]. However, these studies may have underestimated the incidence of lung pathologies for the following reasons: Firstly, EBCT or MDCT scans of the heart were obtained with a small field of view $[10,11,14]$. Therefore, the lateral and apical aspects of the lung were not completely visualized and relevant pulmonary nodules may have been missed. Secondly, not all investigators routinely calculated a dedicated lung window $[11,14]$. In our study, an axial lung window with a sharp kernel of the entire thorax was routinely calculated and displayed for further analysis. However, we believe that the main reason for the relatively high rate of lung cancer in our study was the patients' age. The vascular patients included in our study were approximately ten years older than the patients presented in the abovementioned large cardiac CT studies with an average patient age below 60 years [10-12].

Regarding the patients' age, our study population is rather comparable to studies with patients undergoing CTA before transcatheter aortic valve implantation (TAVI) [7, 15-17]. In the TAVI trial of Ben-Dor et al., the overall rate of unexpected malignancy was $4.2 \% .1 .2 \%$ of the patients were diagnosed with lung cancer [7].

The limitations of our study are as follows: We only reviewed the official radiological reports and no secondary evaluation of the original CT scans was performed. Due to partially incomplete followup, we may have underestimated the prevalence of malignant diseases. This is critical in patients with non-calcified pulmonary nodules, since these findings need follow-up imaging for up to 24 months. However, 17 of 23 patients (74\%) with a pulmonary nodule $>8 \mathrm{~mm}$ had complete follow-up available. Another weakness is the thickness of $5 \mathrm{~mm}$ for our standard lung window reconstruction that may have led to underestimation of small pulmonary nodules. Furthermore, the lack of a portal-venous phase in our standard CT angiography protocol due to dose restrictions may impair the diagnosis of masses in the parenchymatous abdominal organs, especially in the liver. Finally, we did not analyze the rate of alteration in treatment plans, delay of treatment, and cost increase due to unexpected findings as other studies did $[8,15]$.

\section{Conclusion}

With the increasing number of surgical and interventional vascular procedures, preoperatively performed CTA examination of the body in elderly vascular patients will reveal multiple unexpected extravascular findings that might change the course of the patient. This underlines the importance of a thorough and comprehensive analysis of every CTA scan of this patient population by a senior radiologist. Especially noteworthy are malignant tumors of the lung, as this tumor entity had the highest incidence (10/806; $1.2 \%$ ) in our study population comprising patients with vascular diseases.

\section{Conflict of Interest}

The authors declare that they have no conflict of interest. 


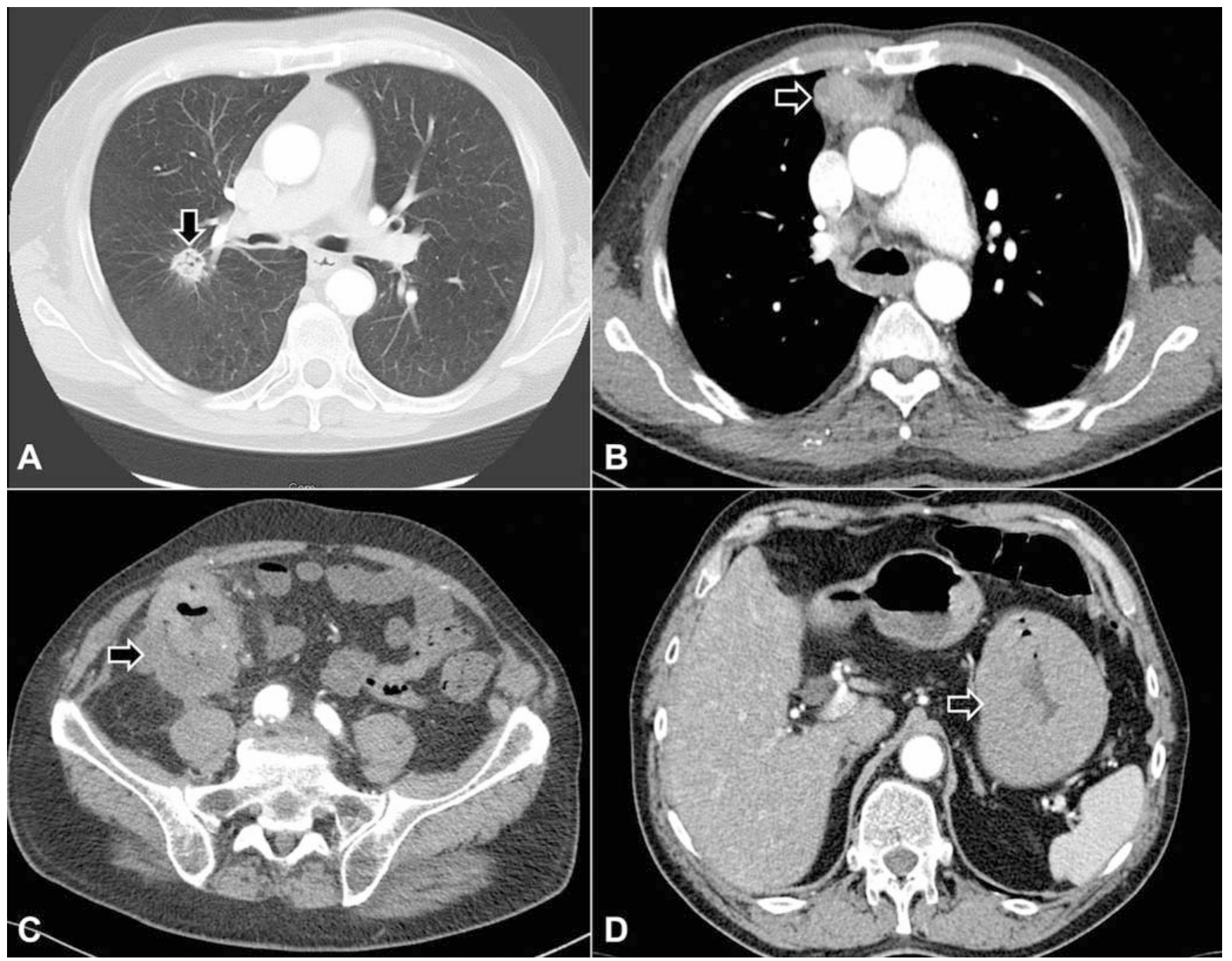

- Fig. 1 A CTA of a 62-year-old male patient with aortoiliac occlusive disease. Reconstruction of the lung showed an unsuspected spiculated mass in the upper lobe of the right lung (arrow). Bronchial biopsy revealed the diagnosis of a bronchial carcinoma. B CTA of a 62-year-old male patient with suspected aortic aneurysm. On axial images of the thorax, a suspicious mass in the anterior portion of the mediastinum was detected (arrow) and a thymus cancer was later diagnosed via biopsy. C Axial CTA of a 73-year-old male patient with Marfan syndrome and aortic dissection showed thickening of the cecum wall. Endoscopic biopsy confirmed the diagnosis of colorectal cancer. D Axial slices of a 61-year-old male patient with thickening of the gastric wall due to neuroendocrine cancer.

- Abb. 1 A CTA eines 62-jährigen, männlichen Patienten mit aortoiliakaler Verschlusskrankheit. Die Lungenrekonstruktion zeigte unerwartet einen spikulierten Herd im rechten Oberlappen (Pfeil). Eine anschließende Biopsie bestätigte die Diagnose eines Bronchialkarzinoms. B CTA eines 62jährigen, männlichen Patienten mit Verdacht auf ein Aortenaneurysma. Auf axialen Schichten des Thorax zeigte sich eine suspekte Raumforderung im anterioren Mediastinum (Pfeil), im Verlauf wurde die Diagnose eines Thymuskarzinoms mittels Biopsie gestellt. C Die axiale Schicht einer CTA eines 73-jährigen, männlichen Patienten mit Marfan-Syndrom und Aortendissektion zeigte eine Verdickung der Zökum-Wand. Die endoskopische Biopsie bestätigte die Diagnose eines kolorektalen Karzinoms. D Axiale Schicht einer CTA eines 61-jährigen, männlichen Patienten mit einer Verdickung der Magenwand aufgrund eines neuroendokrinen Karzinoms. 


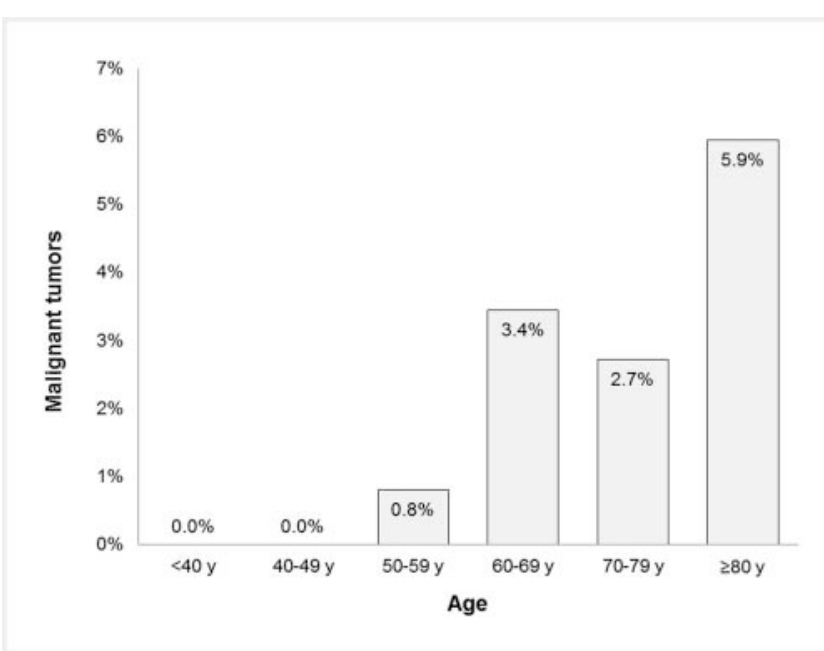

- Fig. 2 Incidence of malignant tumors in 806 patients depending on age.

- Abb. 2 Inzidenz von Malignomen in 806 Patienten, abhängig von der Altersgruppe.

\section{References}

[1] Anderson JL, Halperin JL, Albert NM et al. Management of patients with peripheral artery disease (compilation of 2005 and 2011 ACCF/AHA guideline recommendations): a report of the American College of Cardiology Foundation/American Heart Association Task Force on Practice Guidelines. Circulation 2013; 127: 1425-1443

[2] Moll FL, Powell JT, Fraedrich G et al. Management of abdominal aortic aneurysms clinical practice guidelines of the European society for vascular surgery. European journal of vascular and endovascular surgery : the official journal of the European Society for Vascular Surgery 2011; 41 (Suppl. 1): S1-S58

[3] MacMahon H, Naidich DP, Goo JM et al. Guidelines for Management of Incidental Pulmonary Nodules Detected on CT Images: From the Fleischner Society. Radiology 2017; 284: 229-234

[4] Israel GM, Bosniak MA. How I do it: evaluating renal masses. Radiology 2005; 236: $441-450$
[5] Indes JE, Lipsitz EC, Veith FJ et al. Incidence and significance of nonaneurysmal-related computed tomography scan findings in patients undergoing endovascular aortic aneurysm repair. Journal of vascular surgery 2008; 48: 286-290

[6] Belgrano M, Pozzi MucelliF, Spadacci A et al. Prevalence of extravascular collateral findings during 64-slice $\mathrm{CT}$ angiography of the abdominal aorta and lower limbs. Radiol Med 2010; 115: 983-996

[7] Ben-Dor I, Waksman R, Hanna NN et al. Utility of radiologic review for noncardiac findings on multislice computed tomography in patients with severe aortic stenosis evaluated for transcatheter aortic valve implantation. Am J Cardiol 2010; 105: 1461 - 1464

[8] McDougal JL, Valentine RJ, Josephs S et al. Computed tomographic angiography has added value in patients with vascular disease. Journal of vascular surgery 2006; 44: $998-1001$

[9] Naidu SG, Hara AK, Brandis AR et al. Incidence of highly important extravascular findings detected on CT angiography of the abdominal aorta and the lower extremities. Am J Roentgenol 2010; 194: 1630 1634

[10] Horton KM, Post WS, Blumenthal RS et al. Prevalence of significant noncardiac findings on electron-beam computed tomography coronary artery calcium screening examinations. Circulation 2002; 106: 532-534

[11] Hunold P, Schmermund A, Seibel RM et al. Prevalence and clinical significance of accidental findings in electron-beam tomographic scans for coronary artery calcification. Eur Heart J 2001; 22: 1748-1758

[12] Machaalany J, Yam Y, Ruddy TD et al. Potential clinical and economic consequences of noncardiac incidental findings on cardiac computed tomography. J Am Coll Cardiol 2009; 54: 1533-1541

[13] Onuma Y, Tanabe K, Nakazawa G et al. Noncardiac findings in cardiac imaging with multidetector computed tomography. J Am Coll Cardiol 2006; 48: 402-406

[14] Mueller J, Jeudy J, Poston R et al. Cardiac CT angiography after coronary bypass surgery: prevalence of incidental findings. American journal of roentgenology 2007; 189: 414-419

[15] Goitein O, Di Segni E, Eshet Y et al. Non-Valvular Findings before TransCatheter Aortic Valve Implantation and their Impact on the Procedure. Isr Med Assoc J 2015; 17: 764-767

[16] Gufler H, Schulze CG, Wagner S. Incidental findings in computed tomographic angiography for planning percutaneous aortic valve replacement: advanced age, increased cancer prevalence? Acta Radiol 2014; 55: $420-426$

[17] Staab W, Bergau L, Lotz J et al. Prevalence of noncardiac findings in computed tomography angiography before transcatheter aortic valve replacement. J Cardiovasc Comput Tomogr 2014; 8: 222-229 